\title{
Anaesthesia Management of a Patient with Glucose-6-Phosphate Dehydrogenase Deficiency Undergoing Total Thyroidectomy
}

\author{
Muhammad Yasir and Anwar ul Huda \\ Department of Anaesthesia, Security Forces Hospital, Riyadh, Saudi Arabia
}

\begin{abstract}
We present here, anaesthesia management of a patient having glucose-6-phosphate dehydrogenase (G6PD) deficiency who underwent thyroidectomy. The main concern is to avoid any precipitating factor which could lead to oxidative stress in these patients. There is very limited data available on anaesthesia management of thyroid surgery in such patients.
\end{abstract}

Key Words: Glucose-6-phosphate dehydrogenase deficiency, Oxidative stress, Anaesthesia management.

How to cite this article: Yasir M, Huda AU. Anaesthesia Management of a Patient with Glucose-6-Phosphate Dehydrogenase Deficiency Undergoing Total Thyroidectomy. J Coll Physicians Surg Pak 2020; 30(10):1090-1091.

\section{INTRODUCTION}

Glucose-6-phosphate dehydrogenase (G6PD) deficiency is most widely prevalent disorder in the world, ${ }^{1}$ mainly reported in Africa, Mediterranean Europe, Middle East, Southeast Asia and the Pacific Islands. ${ }^{2}$ G6PD is the enzyme responsible for catalysing initial reaction in pentose phosphate pathway (PPP), resulting in the formation of reduced nicotinamide adeninedinucleotide phosphate (NADPH) that keeps gluthathione in reduced form. This reduced gluthathione acts as an scavenger for oxygen derived free radicals and helps maintain cell integrity. ${ }^{3}$

Patients with G6PD deficiency can, therefore, be susceptible to any oxidative stress. Literature suggests few cases of anaesthesia management of these patients; but there is no general consensus about the usage of anaesthetic agents and other drugs in perioperative period in these patients. ${ }^{4.5} \mathrm{We}$, herein, present a successful anaesthesia management of an adult patient with G6PD deficiency undergoing total thyroidectomy.

\section{CASE REPORT}

A 49-year male weighing 83 kilograms presented with multinodular goitre and was planned for total thyroidectomy. He was diagnosed with G6PD deficiency since childhood and the level of enzyme before his surgery was 0.35 units/g of hemoglobin (normal value: $3.4-8.6$ ).

Correspondence to: Dr. Anwar ul Huda, Department of Anaesthesia, Security Forces Hospital, Riyadh, Saudi Arabia

E-mail: hudaanwar90@yahoo.com

Received: July 22, 2019; Revised: October 10, 2019;

Accepted: October 26, 2019

DOI: https://doi.org/10.29271/jcpsp.2020.10.1090
This patient never had any G6PD deficiency-related complications, like haemolysis, jaundice or blood transfusions. His preoperative vitals included heart rate of 73 beats per minute, blood pressure of $127 / 67 \mathrm{mmHg}$, respiratory rate of 16 breaths per minute, and oxygen saturation (SpO2) of $99 \%$ at roomair. All routine preoperative blood investigations were normal except his haemoglobin, which was high $(17.4 \mathrm{gm} / \mathrm{dL})$. He was referred to haematologist, who diagnosed him with secondary polycythaemia because of high altitude residence; and was advised routine care. His thyroid profile was also normal although he complained about neck discomfort. Airway examination revealed Mallampatti score 3, so we anticipated difficultintubation.

Standard intraoperative monitoring was applied including electrocardiogram (ECG), non-invasive blood pressure (NIBP), pulse oximetry (SpO2), end tidal carbon dioxide concentration (ETCO2) and temperature. Two 20-gauge intravenous cannulae were inserted. Pre-oxygenation was performed for three minutes and following this, anaesthesia was induced with intravenous (IV) 200 $\mathrm{mg}$ propofol, 100 ug fentanyl and $6 \mathrm{mg}$ cisatracurium. After three minutes post-induction, he was intubated with size 8 armoured EMG endotracheal tube [NIM FLEX ${ }^{\mathrm{TM}}$ ], using C-Mac. Anaesthesia was maintained at MAC 1-1.1 using desflurane with oxygen in air mixture (50\%). IV remifentanil infusion in titrated dose of 0.05 to $0.15 \mathrm{ug} / \mathrm{kg} /$ minute was used to provide optimal surgical condition without the use of muscle relaxants. IV Phenylephrine infusion was also used in titrated doses of 15 to $50 \mathrm{ug} /$ minute to maintain blood pressure within $20 \%$ of baseline. We administered IV metoclopramide $10 \mathrm{mg}$, granisetron $1 \mathrm{mg}$, dexamethasone $8 \mathrm{mg}$ and paracetamol $1 \mathrm{gm}$. SpO2 was maintained at $98-100 \%$ and ETCO2 as $30-35 \mathrm{mmHg}$ throughout the procedure. Temperature was adequately managed by using forced air warming device placed underneath the patient. Surgery lasted for three hours and was uneventful. Blood loss was approximately $350 \mathrm{ml}$. Ten minutes before extubation, remifentanil infusion was stopped and IV morphine $5 \mathrm{mg}$ was administered. After checking train of four 
responses, IV neostigmine, $2.5 \mathrm{mg}$ and IV atropine, $1 \mathrm{mg}$, was used for reversing muscle relaxant despite we administered last dose of muscle relaxant at induction only. A total of 1.5 litres of Ringer's lactate was administered during the surgery, which was adequate for replacement for perioperative blood loss and maintenance. Postoperative pain was managed using IV pethidine and paracetamol. The repeat haemoglobin after surgery was $14 \mathrm{~g} / \mathrm{dl}$, which seemed to be due to fluid dilution; and the fact that that haemoglobins test was done by sampling venous blood gases (VBGs) in the recovery room. Further testing of haemolysis like unconjugated bilirubin, lactate dehydrogenase, reticulocyte count and peripheral blood smear were not done because there was no signs or symptoms related to haemolysis postoperatively. Patient was observed for two days in the hospital for any complications related to surgery and his pathology. He remained very well and, hence, two days after his surgery, he was discharged from the hospital.

\section{DISCUSSION}

A number of drugs used in anaesthesia like non-steroidal antiinflammatory drugs (NSAIDs), antibiotics e.g, sulphonamides, nitrofurantoinand chloramphenicol, etc and conditions likeperioperative ischemia, hypoxia, hypothermia and acidosis result in formation of free radicals causing oxidative stress and increase risk of haemolysis in G6PD deficient patients. ${ }^{6}$ Anaesthesia agents like isoflurane and sevoflurane, fentanyl and rocuronium are used in these patients without adverse events as suggested by literature and, hence, considered safe. ${ }^{1}$ Although, Altikat et al. ${ }^{5}$ showed that isoflurane, sevoflurane, diazepam and midazolam reduced G6PD activity in an in vitro study. However, sevoflurane and midazolam are controversially discussed in one review and there are case reports of safety of sevoflurane use in patients with G6PD deficiency. ${ }^{4}$

The most effective management of G6PD deficient patients is to prevent haemolysis by avoiding oxidative stress. ${ }^{7}$ A number of factors influence haemolysis in these patients, like type of mutation causing G6PD deficiency, genetic set-up and patient's gender, age of red blood cells and type and dose of agents causing haemolysis. ${ }^{8}$ Immediate signs of acute haemolytic crisis are usually masked during anaesthesia, so these should be closely observed. Hypotension is not considered as a specific indicator of the haemolytic crisis and may not be evident until haematuria is observed. ${ }^{1}$ Laboratory findings considered suggestive of crisis may include low haemoglobin, reticulocytosis, low serum haptoglobin and raised indirect bilirubin and lactate dehydrogenase (LDH). ${ }^{9}$ Once haemolysis is diagnosed, offending agents should be immediately discontinued and urine output should be maintained by using crystalloids infusion along with diuretics. Complete blood count $(\mathrm{CBC})$ should be monitored daily, considering the need for blood transfusion. $^{8}$

Liberal analgesia and anxiolysis should be provided in perioperative period while managing these patients. G6PD levels are also found to be reduced in platelets althoug h coagulation parameters are usually normal in these patients. ${ }^{10}$ In this case, we avoided the use of drugs which are known to induce oxidative stress. We also administered adequate analgesics and anxiolytics in the perioperative period and, hence, resulted in an uneventful clinical course.

\section{PATIENT'S CONSENT:}

Informed consent was taken from the patient.

\section{CONFLICT OF INTEREST:}

Authors declared no conflict of interest.

\section{AUTHORS' CONTRIBUTION:}

MY: Concept, primary anaesthetist, literature search, manuscript writing and editing, final approval.

AUH: Literature search, manuscript writing and editing, final approval.

\section{REFERENCES}

1. Elyassi $A R$, Rowshan HH. Perioperative management of the glucose-6-phosphate dehydrogenase deficient patient: A review of literature. Anesth Prog 2009; 56(3):86-91. doi: 10.2344/0003-3006-56.3.86.

2. Mehta A, Mason PJ, Vulliamy TJ. Glucose-6-phosphate dehydrogenase deficiency. Best Practice Res Clin Haematol 2000; 13(1):21-38. doi: 10.1053/beha.1999.0055.

3. Sahin S, Nal M, Kaya G, Alagol A, Günday I. Anesthesia management of a patient with glucose-6-phosphate dehydrogenase deficiency. Int J Anesthesiol 2006; 14(2).

4. Valiaveedan S, Mahajan C, Rath GP, Bindra A, Marda MK. Anaesthetic management in patients with glucose-6phosphate dehydrogenase deficiency undergoing neurosurgical procedures. Indian J Anaesth 2011; 55(1):68-70. doi: 10.4103/0019-5049.76597.

5. Altikat S, Ciftçi M, Büyükokurolu ME. In vitro effects of some anesthetic drugs on enzymatic activity of human red blood cell glucose 6-phosphate dehydrogenase. Pol J Pharmacol 2002; 54(1):67-71.

6. Doshi CM, Tandake SR, Mohite SN, Nagaria A. Perioperative management in a case of glucose 6 phosphate dehydrogenase deficiency undergoing orthopaedic surgery. Saudi J Anaesth 2015; 9(4):490-1. doi: 10.4103/1658-354X. 159485.

7. Cappellini MD, Fiorrelli G. Glucose 6 phospghate dehydrogenase deficiency. Lancet 2008; 371(9606):64-74. doi.org/10.1016/S0140-6736 (08)60073-2.

8. Martin LD, Casella ES. Anaesthesia and G6PD deficiency in a child with congenital heart disease. J Cardiothorac Vasc Anesth 1991; 5(6):596-9. doi.org/10.1016/1053-0770 (91)90014-K.

9. Bhageria V, Chowdhury I, Goel N, Pathak S. Anaesthetic management of a patient with glucose-6phosphate dehydrogenase deficiency undergoing robotic-assisted laparoscopic radical prostatectomy. J Soc of Anesthesiologists of Nepal (JSAN) 2016; 3(2):93-95.

10. Smith CL, Snowdon SL. Anaesthesia and glucose-6phosphate dehydrogenase deficiency: A case report and review of literature. Anaesthesia 1987; 42(3):281-8. doi: 10.1111/j.1365-2044.1987.tb03040.x. 